\title{
A BIOMECHANICAL EVALUATION OF SUTURE ANCHORS IN REPAIR OF THE ROTATOR CUFF
}

\author{
D. J. ROSSOUW, B. J. McELROY, A. A. AMIS, R. J. H. EMERY \\ From St Mary's Hospital and the Imperial College of Science, Technology and Medicine, London, \\ England
}

Repair of the rotator cuff requires secure reattachment, but large chronic defects cause osteoporosis of the greater tuberosity which may then have insufficient strength to allow proper fixation of the tendon. Recently, suture anchors have been introduced, but have not been fully evaluated.

We have investigated the strength of suture-to-anchor attachment, and the use of suture anchors in repairs of the rotator cuff either to the greater tuberosity or the lateral cortex of the humerus. The second method gave a significant increase in the strength of the repair ( $p=0.014)$.

The repairs were loaded cyclically and failed at low loads by cutting into bone and tendon, casting doubt on the integrity of the repair in early mobilisation after surgery. Repairs with suture anchors did not perform better than those with conventional transosseous attachment.

J Bone Joint Surg [Br] 1997;79-B:458-61

Received 7 June 1996; Accepted after revision 1 November 1996

Large tears of the rotator cuff often cause considerable disability. Codman ${ }^{1}$ first reported success in the repair of these lesions, but early failure of the repair of large defects is common, in spite of improvements in surgical technique. $^{2}$ The McLaughlin method ${ }^{3}$ of reattaching the tendon into a bony trough is widely practised. The ideal fixation would maintain the abutment of tendon to bone to allow

D. J. Rossouw, FRCS, Senior Orthopaedic Registrar

B. J. McElroy, FRCS, Orthopaedic Registrar

The Royal Berkshire Hospital, London Road, Reading, Berkshire RG1 $5 \mathrm{AN}, \mathrm{UK}$

A. A. Amis, $\mathrm{PhD}$, Reader in Orthopaedic Biomechanics

Mechanical Engineering Department, Imperial College of Science, Technology and Medicine, Exhibition Road, London SW7 2BX, UK.

R. J. H. Emery, FRCS Ed, Consultant Orthopaedic Surgeon St Mary's Hospital, Praed Street, London W2 4NY, UK.

Correspondence should be sent to Dr A. A. Amis.

(C)1997 British Editorial Society of Bone and Joint Surgery 0301-620X/97/36983\$2.00 physiological repair by Sharpey's fibres during rehabilitation of the shoulder. ${ }^{4}$ Early mobilisation, however, jeopardises the integrity of a rotator cuff repair. The dilemma between protecting a repair and early mobilisation to prevent stiffness and weakness has yet to be resolved.

Suture anchors are now used during arthroscopic stabilisation of the shoulder since they allow minimally-invasive placement, but they have not been fully evaluated. Disuse osteoporosis of the greater tuberosity may make this an inappropriate site for fixation of a suture anchor, and we considered that anchorage to the adjacent lateral humeral cortex would be stronger.

Previous tests of repair strength ${ }^{5-9}$ used 'static' distraction by a single elongation to failure. As early movement of the shoulder is required after operation, we felt that cyclic loading would be a more realistic method of evaluating the strength of a repair.

\section{MATERIALS AND METHODS}

The suture material used was No. 2 braided polyester (Surgibond, Redditch, UK) which has a strength of $132 \pm$ $5 \mathrm{~N}$ at $23 \%$ elongation. It was chosen because of its strength and stiffness. 10

The suture anchor was the Mitek GII (Mitek Products; Ethicon Inc, Boston, Massachusetts) which has a bulletshaped titanium-alloy body with an eye for suture attachment and two nitinol wire barbs, which catch in the bone.

For the in vitro tests we used pairs of fresh-frozen cadaver shoulders obtained at postmortem. They comprised the proximal $100 \mathrm{~mm}$ of the humerus with all its capsular and muscle attachments, and approximately $80 \mathrm{~mm}$ of supraspinatus. The specimens had a mean age of 67 years similar to that of patients having surgery to the cuff, but did not show the osteoporosis often found in this condition.

Static tensile tests

Suture-anchor attachment. Since the attachment eye of the suture anchor was rounded at the end, but had sharp edges at the sides, the suture-to-anchor attachment was tested in line with the anchor (axial load) and at $90^{\circ}$ to it (transverse load), with six specimens in each group. A $200 \mathrm{~mm}$ length of suture was threaded through the anchor forming a $100 \mathrm{~mm}$ loop. The suture ends and the suture anchor were clamped in the soft-faced vice jaws of an Instron 1122 
materials testing machine and the suture extended to failure at $50 \mathrm{~mm} / \mathrm{min}$.

Rotator-cuff repairs. The shaft of the humerus was cleared of soft tissue and mounted in a steel pot using polymethylmethacrylate bone cement. The soft tissue was dissected from the head leaving the supraspinatus muscle with small amounts of cuff tissue on each side. A $30 \mathrm{~mm}$ defect was created by cutting across the attachment of the supraspinatus, and a matching $30 \mathrm{~mm}$ trough, $3 \mathrm{~mm}$ deep and $5 \mathrm{~mm}$ wide, was formed medial to the greater tuberosity at the edge of the articular cartilage.

Holes were drilled $12 \mathrm{~mm}$ apart for two Mitek anchors in each specimen, either in the base of the trough or in the lateral cortex, using the Mitek $2.7 \mathrm{~mm}$ drill. The holes in the lateral cortex were $25 \mathrm{~mm}$ distal to the tip of the greater tuberosity, which would avoid the axillary nerve in clinical practice. Four bone tunnels, $2 \mathrm{~mm}$ in diameter, were drilled from the base of the trough to the lateral cortex, $8 \mathrm{~mm}$ apart, for the sutures in specimens with laterally-placed anchors.

Three anchor placements were tested:

1) in the base of the trough (Fig. 1a);

2) in the lateral cortex of the humerus, perpendicular to the surface (Fig. 1b); and
Fig. 1a

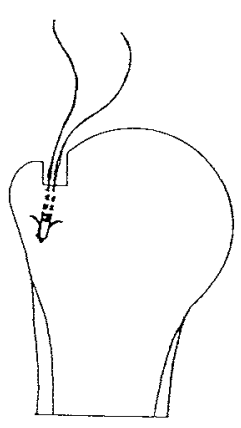

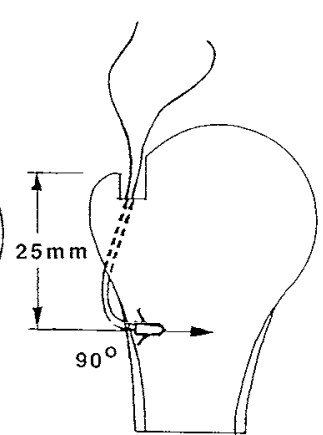

Fig. 1b

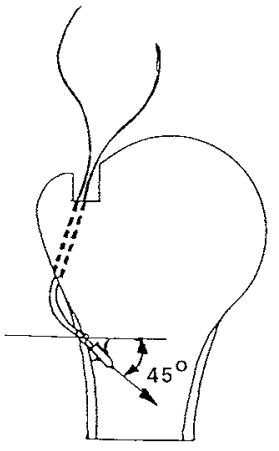

Fig. 1c
The three sites of insertion of the suture anchor.

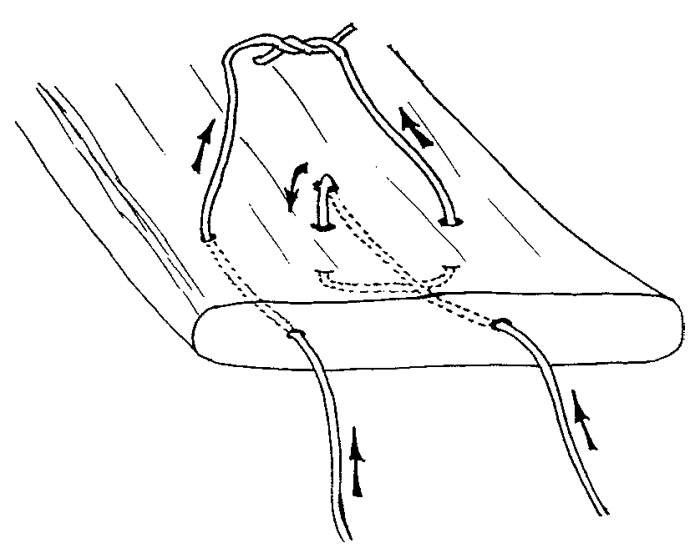

Fig. 2

Part of the method of tendon suture. Two such sutures, plus mattress sutures, were used in each repair.
3 ) in the same site in the lateral cortex, but directed $45^{\circ}$ caudally (Fig. 1c).

In methods 2 and 3, the sutures were passed proximally through the bone tunnels, leaving four sutures in the base of the trough in all groups. The tendon was sutured using a modified Snyder technique ${ }^{7}$ (Fig. 2): one end of each suture was not locked in the tendon, allowing it to slide through the anchor and pull the tendon into the trough. Two such sutures were used in each repair, each with an anchor. Two supplementary horizontal mattress sutures with a single pass through the tendon were placed across the surface of the tendon defect and through the bone of the greater tuberosity, where they were knotted on the lateral aspect, inverting the tendon edge, so that eight suture strands crossed each repair. The tissues were transected on either side of the supraspinatus.

Six pairs of shoulders were used to compare methods 1 and 2 and a further six pairs to compare methods 2 and 3.

During testing, the supraspinatus was grasped in cryojaws ${ }^{11}$ with the humerus held in an angled device simulating $30^{\circ}$ abduction. The repair was loaded to failure at $50 \mathrm{~mm} / \mathrm{min}$ and the relationship of the force to the crosshead movement recorded graphically. The loads at which the tendon end was pulled above the rim of the trough when the repair failed, and the mode and site of failure were noted.

The results were tested for significant differences between groups using Student's unpaired $t$-test for the suture-to-anchor attachment strengths, and the paired $t$-test for the paired cadaver specimens.

Cyclic load tests. Seven pairs of shoulders were prepared as above. In one of each pair (side A), the defects in the supraspinatus were repaired with suture anchors as in method 3. In the other (side B), the repair was the same in the tendon, but the sutures rested on the bony bridges between the tunnels on the lateral aspect.

The specimens were mounted in the Instron machine as described above. Ten load cycles from zero to $50 \mathrm{~N}$ were applied at $50 \mathrm{~mm} / \mathrm{min}$. The maximum force was then increased to $100 \mathrm{~N}$ for ten cycles, and by $50 \mathrm{~N}$ for each subsequent set of ten cycles until failure. Graphs were plotted for the force versus the crosshead displacement.

\section{RESULTS}

\section{Static tensile tests}

Suture-anchor attachment. The sutures failed in transverse loading by cutting on the edge of the Mitek eye at $42 \pm 4 \mathrm{~N}$. In axial loading suture failure occurred at the Mitek eye at $200 \pm 9 \mathrm{~N}(\mathrm{p}<0.001)$.

Rotator cuff repairs. Method 1, with the anchors in the trough, failed at $147 \pm 74 \mathrm{~N}$, and method 2, with the anchors at $90^{\circ}$ to the lateral cortex, at $363 \pm 120 \mathrm{~N}$ $(\mathrm{p}=0.014)$.

Comparing method 2 with method 3, with the anchors at $45^{\circ}$ to the lateral cortex, failure was at $299 \pm 59 \mathrm{~N}$ and 322 


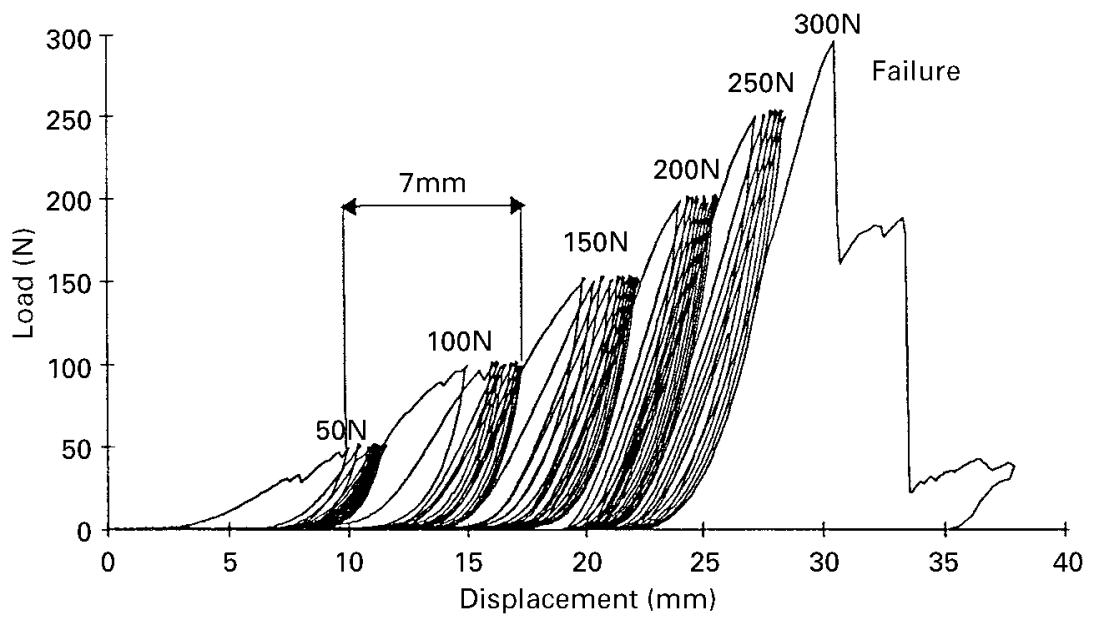

Fig. 3

Typical load-versus-displacement graph for cyclic loading of a method 3 cuff repair (suture anchors in lateral cortex, $45^{\circ}$ to surface), showing elongation of $7 \mathrm{~mm}$ between the first and the 20th load cycles. There was elongation of approximately $20 \mathrm{~mm}$ between the first and final loadings.

$\pm 54 \mathrm{~N}$, respectively $(\mathrm{p}=0.183)$.

Method 1 always failed by anchor extraction. In methods 2 and 3 all the anchors remained in situ and failure was by a combination of breakage of the suture at the anchor or away from it, and by cutting out of the suture from the tendon. Early failure occurred by the suture cutting on the eye if the anchor protruded from the surface in method 2. Cyclic load tests. All repairs showed permanent incremental deformation with each load cycle and a larger elongation during the step-up to a larger maximum force (Fig. 3). The sutures cut through the tuberosity and the tendon with a sawing action as they stretched and con- tracted, as well as gripping the tendon fibres tighter (Fig. 4). After the $100 \mathrm{~N}$ increment (i.e., a total of only 20 load cycles), there was a permanent deformation of $6.7 \pm$ $1.8 \mathrm{~mm}$ for side $\mathrm{A}$ and $4.9 \pm 1.5 \mathrm{~mm}$ for side $\mathrm{B}$, with sutures lying over the bone $(\mathrm{p}=0.155)$.

Ultimate failure occurred at $227 \pm 41 \mathrm{~N}$ for side $\mathrm{A}$ and $238 \pm 80 \mathrm{~N}$ for side $\mathrm{B}$. The mean deformation at failure, allowing for gap formation at the repair site, was $18 \mathrm{~mm}$ in side A and $14 \mathrm{~mm}$ in side B (Figs. 3 and 4). Failure was by breakage of the suture at the knots and suture anchors; no anchors dislodged and the tendon attachments all remained intact.
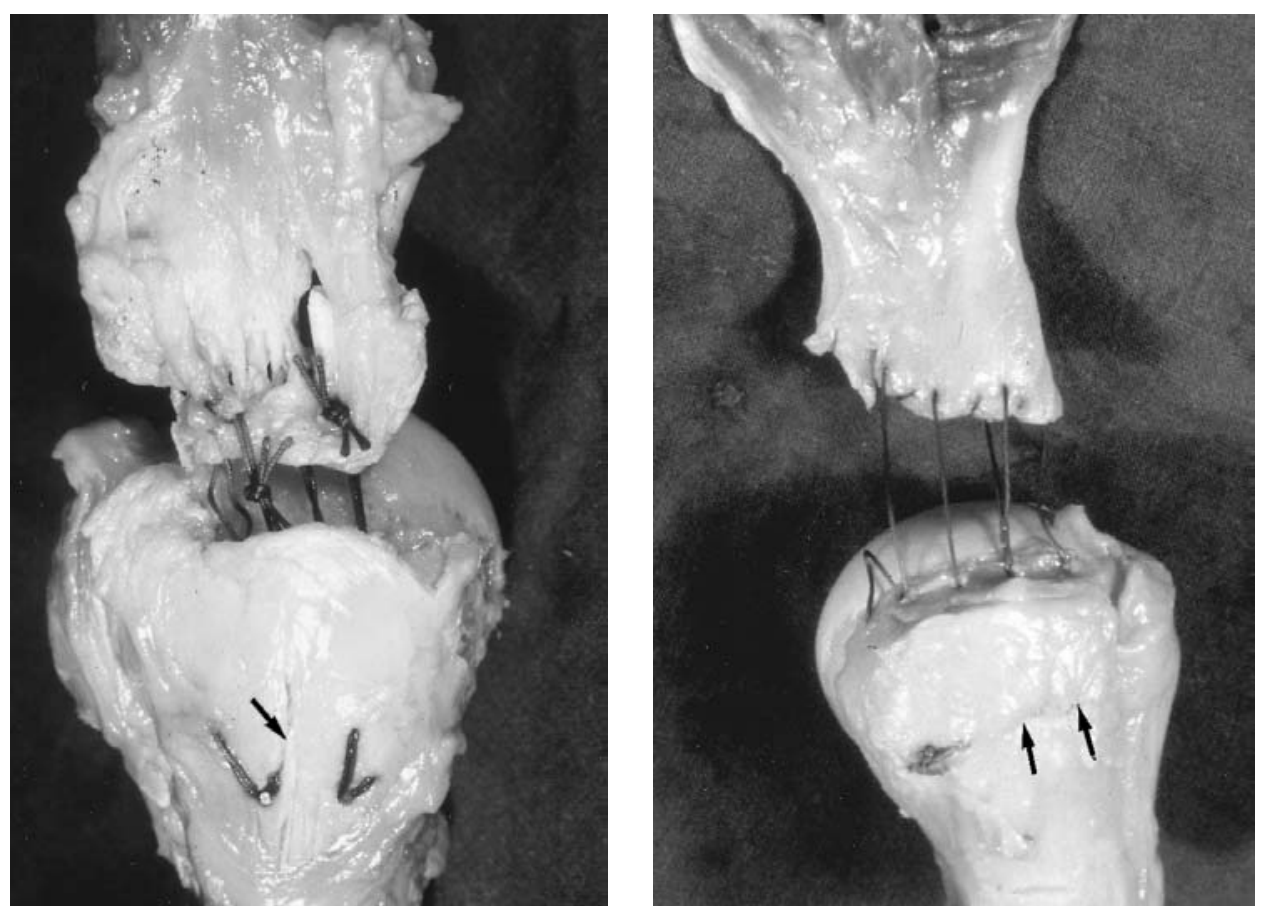

Fig. 4

Typical appearances of repairs after cyclic loading (a) with, and (b) without suture anchors. Note how the sutures have sawn into the bones (arrows) and torn into the tendon. The suture anchors did not move. These specimens did not have superficial mattress sutures. 


\section{DISCUSSION}

The strength of repairs of the rotator cuff is compromised by the poor quality of tissues adjacent to a chronic defect. Attempts have been made to increase the strength by using polymer pads to protect the bone from 'cheesewiring', and by employing multilooped suture techniques to grasp the tendon.

Suture anchors provide a relatively quick and easy method for reattaching a supraspinatus tendon. We were, however, concerned that it might not be appropriate to place the anchors into the osteoporotic cancellous bone seen in a chronic cuff defect, particularly since early rehabilitation subjects repairs to cyclic forces. Although Hecker et al ${ }^{9}$ felt that suture anchors gave sufficient strength in a McLaughlin trough, Gerber et $\mathrm{al}^{8}$ had poor results in the osteoporotic tuberosities of specimens with defects of the rotator cuff.

Amis ${ }^{12}$ found that the pull-out strength of ligament anchors was proportional to the cortical thickness, and Hecker et $\mathrm{al}^{9}{ }^{9}$ reported increased strength when anchors were placed into metaphyseal rather than cancellous bone. These results are not surprising since cortical bone is approximately 30 times stronger than cancellous bone. ${ }^{13,14}$ Amis ${ }^{12}$ concluded that, since the cortex thickens away from the joint, anchors should be placed as far from it as possible, subject to surgical restraints, but with sutures this must be balanced against elastic extension, which is proportional to their length. The tendon end was pulled back to the edge of the trough at approximately $200 \mathrm{~N}$, and even further after cyclic loading (Fig. 3). Movement of the tendon relative to the trough may affect healing.

Since the barbs on the anchors were small, they pulled through cancellous bone until they reached the cortex. Thus moving the anchors from the cancellous tuberosity to the lateral cortex significantly increased strength and none dislodged.

In the unloaded arm a supraspinatus tension of $300 \mathrm{~N}$ has been estimated in $30^{\circ}$ active abduction ${ }^{15}$. Our results suggest that a rotator cuff repair with lateral cortical anchorage will have sufficient strength to sustain early rehabilitation with assisted passive movement. Repetitive application of even small forces, however, caused significant gap formation. Early mobilisation may therefore be detrimental to the reattachment of tendon to bone, and our clinical practice has changed accordingly.
The method of repair which we describe can be performed through a limited surgical exposure. We found no advantage from the use of suture anchors; failure occurred elsewhere. Further work is needed to investigate the strengths of surgical techniques and to reduce the high failure rate of repairs. Tests must include cyclic as well as static loading.

We thank the Pathology Departments at Barnet General and Wexham Park Hospitals for the specimens, Harvard Healthcare for the Mitek anchors, and the Arthritis and Rheumatism Council for the Instron machine. This work was funded by the Joint Standing Research Committee at St Mary's Hospital, and the Hanson Trust.

No benefits in any form have been received or will be received from a commercial party related directly or indirectly to the subject of this article.

\section{REFERENCES}

1. Codman EA. Rupture of the supraspinatus tendon. Boston Medical \& Surgical Journal 1911 Vol clxiv (2) 708-10, reprinted in Clin Orthop 1990;254:3-26.

2. Harryman DT, Mack LA, Wang KY, et al. Repairs of the rotator cuff: correlation of functional results with integrity of the cuff. $J$ Bone Joint Surg [Am] 1991;73-A:982-9.

3. McLaughlin HL. Lesions of the musculotendinous cuff of the shoulder: the exposure and repair of tears with retraction. J Bone Joint Surg 1944;26:31-51.

4. Cofield RH. Current concepts review: rotator cuff disease of the shoulder. J Bone Joint Surg [Am] 1985;67-A:974-9.

5. France EP, Paulos LE, Harner CD, Straight CB. Biomechanical evaluation of rotator cuff fixation methods. Am J Sports Med 1989; 17:176-81.

6. Sward L, Hughes JS, Amis AA, Wallace WA. The strength of surgical repairs of the rotator cuff: a biomechanical study on cadavers. J Bone Joint Surg [Br] 1993;74-B:585-8.

7. Snyder SJ. Evaluation and treatment of the rotator cuff. Orthop Clin North Am 1993;24:173-92.

8. Gerber C, Schneeberger AG, Beck M, Schlegel U. Mechanical strength of repairs of the rotator cuff. J Bone Joint Surg [Br] 1994; 76-B:371-80.

9. Hecker AT, Shea M, Hayhurst JO, et al. Pull-out strength of suture anchors for rotator cuff and Bankart lesion repairs. Am J Sports Med 1993;21:874-9.

10. Trail IA, Powell ES, Noble J. An evaluation of suture materials used in tendon surgery. J Hand Surg [Br] 1989;14:422-7.

11. Riemersma DJ, Schamhardt HC. The cryo-jaw: a clamp designed for in-vitro rheology studies of horse digital flexor tendons. J Biomech 1982;15:619-20.

12. Amis AA. The strength of artificial ligament anchorages: a comparative experimental study. J Bone Joint Surg [Br] 1988;70-B: 397-403.

13. Reilly DT, Burstein AH. The mechanical properties of cortical bone. J Bone Joint Surg [Am] 1974;56-A:1001-22.

14. Van Auderkercke R, Martens M. Mechanical properties of cancellous bone. In: Hastings G, Ducheyne P, eds. 'Natural and living biomaterials'. Boca Raton: CRC Press, 1984:89-98.

15. Wallace WA. Evaluation of the forces, the ICR and the neutral point during abduction of the shoulder. Trans 30th Meeting of the Orthopaedic Research Society, Atlanta, 1984:5. 